\title{
A STUDY OF CLINICO-PATHOLOGICAL PARAMETERS IN PATIENTS OF CARCINOMA LARYNX
}

\author{
Kartikeya Purohit ${ }^{1}$, Sampan Singh Bist², Vinish Agarwal ${ }^{3}$, Smita Chandra ${ }^{4}$
}

1Junior Resident, Department of Otorhinolaryngology \& Head-Neck Surgery, Himalayan Institute of Medical Sciences, Jollygrant, Dehradun.

2Professor \& HOD, Department of Otorhinolaryngology \& Head-Neck Surgery, Himalayan Institute of Medical Sciences, Jollygrant, Dehradun.

${ }^{3}$ Assistant Professor, Department of Otorhinolaryngology \& Head-Neck Surgery, Himalayan Institute of Medical Sciences, Jollygrant, Dehradun.

${ }_{4}^{4}$ Associate Professor, Department of Pathology, Himalayan Institute of Medical Sciences, Jollygrant, Dehradun.

\begin{tabular}{l} 
ABSTRACT \\
\hline BACKGROUND \\
Incidence of carcinoma larynx in India reported to be 1.3 to 8.8 per 100,000 populations in six different regions of the country. \\
The main risk factors for development of carcinoma larynx are consumption of smoke tobacco and alcohol. The aim of this study \\
was to evaluate clinico-pathological parameters in patients with carcinoma larynx.
\end{tabular}

\section{MATERIAL AND METHOD}

A total of 110 patients newly diagnosed with carcinoma larynx were included in this study after taking informed consent from the patient and clearance from the ethics committee. Previously treated larynx cancer patients with recurrence were excluded.

\section{RESULT}

Pain on swallowing was the commonest presenting symptom present in 101 (91.81\%) patients. Smoke tobacco consumption was present in 104 (94.54\%) patients, smokeless tobacco consumption was present in 12 (10.90\%) patients and alcohol consumption was present in 94 (85.45\%) patients with cancer larynx. Most of the patients had inadequate dietary intake as per recommended dietary allowance.

\section{CONCLUSIONS}

The most common site involved was supraglottis seen in 70 (63.63\%) patients. Most of the patients presented with stage III cancer in 43 (39.09\%) patients. Squamous cell carcinoma was the histopathological variant seen in all patients in our study. Moderately differentiated squamous cell carcinoma was the most common squamous cell carcinoma variant seen present in 62 (56.36\%) patients.

\section{KEYWORDS}

Larynx, Cancer, Clinico-Pathological.

HOW TO CITE THIS ARTICLE: Purohit K, Bist SS, Agarwal V, et al. A study of clinico-pathological parameters in patients of carcinoma larynx. J. Evolution Med. Dent. Sci. 2016;5(34):1876-1880, DOI: 10.14260/jemds/2016/443

\section{INTRODUCTION}

Carcinoma larynx is quite common in India. Smoking is the most important risk factor for laryngeal cancers. Death from laryngeal cancer is 20 times more likely for heaviest smokers than for non-smokers.[1] Smokers of non-filtertip cigarettes have a higher cancer risk than those smoking filtertip cigarettes. With respect to carcinogenesis, alcohol and nicotine consumed together develop a synergistic action and have a multiplicative effect on the cancer risk. [2] Tobacco smoke contains multiple classes of established carcinogens including benzopyrenes, polycyclic aromatic hydrocarbons, and tobacco-specific nitrosamines.[3] Indians are affected more than westerns. Its current incidence in U.S. is 5 in 100,000 populations. [4]

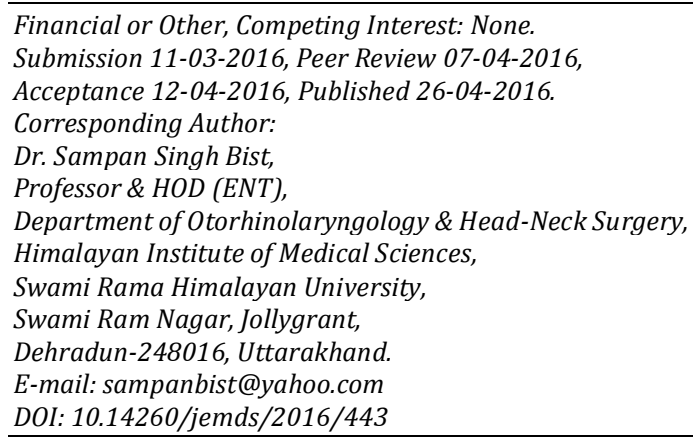

Its current incidence in U.S. is 5 in 100,000 populations.[4] Incidence of carcinoma larynx in India reported to be 1.3 to 8.8 per 100,000 populations in six different regions of the country.[5] Incidence in females is also increasing as more females are taking to smoking. Patients are mostly in the age group of 40 to 70 years, but younger people may also be affected. Most of carcinoma larynx is squamous cell carcinomas. Most malignancies originate in glottis followed by supraglottis and subglottis. Chronic hoarseness is the most common early symptom.[6] Other symptoms of laryngeal cancer include pain in neck, dysphagia, dyspnoea, a lump in the neck and stridor.[6]

\section{MATERIALS AND METHODS}

The present study was carried out in the Department of Otorhinolaryngology, at Himalayan Institute of Medical Sciences, Swami Ram Nagar, Dehradun, over a period of 12 months. A total of 110 patients newly diagnosed with carcinoma larynx were included in this study after taking informed consent from the patient and clearance from the ethics committee. Previously treated larynx cancer patients with recurrence were excluded. The patients selected for this study were subjected to a detailed history and complete Otorhinolaryngology and head and neck clinical examination after detailed informed consent. 
Detailed personal history included consumption of smoke tobacco, smokeless tobacco and alcohol intake. As per patient's history, smokeless tobacco consumption was calculated as packets per day and smoke tobacco consumption was calculated in pack years (Number of bidis/cigarettes smoked per day divided by the number of bidis/cigarettes in 1 pack and then multiplied by the number of years the person has smoked). Alcohol consumption was calculated in grams per day (Alcohol by volume (\%) X volume consumed per day (mL) divided by 1000 and then multiplied by 10). Energy was calculated in Kcal/day, fat in grams/day and proteins in grams/day based on patient's regular diet. General examination and vitals of all patients were recorded.

Systemic examination was done to detect distant metastasis. The oral cavity was examined in detail with help of a tongue depressor using head mirror and bull's eye lamp. Suspected area was evaluated by digital palpation. Detailed examination of larynx and pharynx (Oropharynx/hypopharynx) were done by indirect laryngoscopy mirror (No. 3-7) and by diagnostic laryngeal endoscopy using Karl Storz $70^{\circ}$ rigid wide angle laryngeal endoscope $(7 \mathrm{~mm})$ to look for second primary and findings were recorded using Imimo software and printed records were obtained. Nasopharynx was examined by posterior rhinoscopy and findings were confirmed by Karl Storz $0^{\circ}$ Hopkins rod rigid nasal endoscope $(4 \mathrm{~mm})$.

Detailed examination of neck was done including laryngeal framework, laryngeal tenderness, laryngeal crepitus and lymph nodes from level I to level VI. Clinical staging of the tumour was done as per American Joint Committee on Cancer (AJCC) (2012) classification (21). Fine Needle Aspiration Cytology (FNAC) was done by standard technique either using aspiration (Thompson 1982) or without aspiration (Zadela 1987) under all aseptic precautions with a 22-gauge needle for neck swelling. All patients underwent biopsy for histopathological examination under General Anaesthesia (GA) or Local Anaesthesia (LA). Histopathological examination which included type of malignancy, level of differentiation, necrosis, lymphocytic infiltration, mitotic figures and keratinization. Records were maintained.

\section{OBSERVATION AND RESULTS}

In present study, the age distribution of patients ranged from 24 to 92 years of age with mean age of $51.92 \pm 13.06$ years. There were 110 patients with cancer larynx in our study, out of which 96 (87.27\%) patients were males and 14 (12.72\%) patients were females.

\begin{tabular}{|c|c|c|c|}
\hline Symptoms & Duration & \multicolumn{2}{|c|}{ No. of Patients } \\
\hline \multirow{2}{*}{ Pain on swallowing } & $0-3$ months & 68 & \multirow{2}{*}{101} \\
\hline & 3-6 months & 33 & \\
\hline \multirow{2}{*}{ Change in voice } & $0-3$ months & 38 & \multirow{2}{*}{57} \\
\hline & 3-6 months & 19 & \\
\hline \multirow{2}{*}{$\begin{array}{l}\text { Difficulty in } \\
\text { swallowing }\end{array}$} & $0-3$ months & 45 & \multirow{2}{*}{95} \\
\hline & 3-6 months & 50 & \\
\hline \multirow{2}{*}{ Swelling in the neck } & $0-3$ months & 32 & \multirow{2}{*}{49} \\
\hline & 3-6 months & 17 & \\
\hline Difficulty in breathing & $0-3$ months & 34 & 34 \\
\hline Earache & $0-3$ months & 35 & \multirow{2}{*}{57} \\
\hline Per oral bleed & $0-3$ months & 22 & \\
\hline $\begin{array}{r}\text { Table 1: Pre } \\
\text { in Cal }\end{array}$ & $\begin{array}{l}\text { Symptc } \\
\text { ynx Pat }\end{array}$ & $1-11$ & \\
\hline
\end{tabular}

Pain on swallowing was the commonest complaint present in 101 (91.81\%) patients followed by difficulty in swallowing complaint present in $95(86.91 \%)$ patients. There were $68(61.81 \%)$ patients with pain on swallowing as commonest complaint presented within 3 months of onset of symptoms. (Table 1). Ulceroproliferative growth pattern was seen in 97 (88.18\%) patients. There was laryngeal widening present in $16(14.54 \%)$ patients, laryngeal tenderness present in $7(6.36 \%)$ patients and absent laryngeal crepitus in $2(1.81 \%)$ patients.

\begin{tabular}{|c|c|c|}
\hline $\begin{array}{c}\text { Type of } \\
\text { Addiction }\end{array}$ & $\begin{array}{c}\text { No. of Patients } \\
\text { (110) }\end{array}$ & Percentage \\
\hline Smoke tobacco & 104 & $94.54 \%$ \\
\hline Smokeless tobacco & 12 & $10.90 \%$ \\
\hline Smoke and smokeless & 12 & $10.90 \%$ \\
\hline $\begin{array}{c}\text { Smoke tobacco and } \\
\text { alcohol }\end{array}$ & 78 & $70.9 \%$ \\
\hline $\begin{array}{c}\text { Smokeless tobacco and } \\
\text { alcohol }\end{array}$ & 6 & $5.45 \%$ \\
\hline $\begin{array}{c}\text { Smoke and smokeless } \\
\text { tobacco with alcohol }\end{array}$ & 10 & $9.09 \%$ \\
\hline \multicolumn{2}{|c|}{ Table 2: Addiction in Cancer Patients (n=110) } \\
\hline
\end{tabular}

Smoke tobacco consumption was present in 104 (94.54\%) patients, smokeless tobacco consumption was present in $12(10.90 \%)$ patients and alcohol consumption was present in $94(85.45 \%)$ patients with cancer larynx. (Table 2). There were $43(44.79 \%)$ male patients and 7 (50\%) female patients with less than 100 grams per day protein intake was the commonest, 41 (42.70\%) male patients and $9(64.28 \%)$ female patients with 41 to 50 grams per day fat intake was the commonest and 40 (41.66\%) male patients with 2001 to $3000 \mathrm{kcal} /$ day energy intake and 5 (35.71\%) female patients with less than $2000 \mathrm{kcal} /$ day energy intake was the commonest.

\begin{tabular}{|c|c|c|}
\hline Subsite & No. of Patients & ( Percentage) \\
\hline \multicolumn{3}{|c|}{ Supraglottis } \\
\hline Epiglottis & 28 & $25.45 \%$ \\
\hline Aryepiglottic folds & 63 & $57.27 \%$ \\
\hline Arytenoid area & 21 & $19.09 \%$ \\
\hline False vocal cords & 55 & $50 \%$ \\
\hline \multicolumn{3}{|c|}{ Transglottis } \\
\hline \multicolumn{3}{|c|}{ Glottis } \\
\hline \multicolumn{3}{|c|}{ Subglottis } \\
\hline True vocal folds & 4 \\
\hline Subglottic area & Table 3: Subsite Distribution of Patients \\
\hline
\end{tabular}

The most common site involved was supraglottis in 70 (63.63\%) patients followed by glottis in 23 (20.90\%) patients then transglottis in $10(9.09 \%)$ patients and lastly subglottis in $7(6.36 \%)$ patients. Cancer larynx patients in our study had involvement of more than one subsite. (Table 3).

\begin{tabular}{|c|c|c|}
\hline $\begin{array}{c}\text { Tumour } \\
\text { Staging }\end{array}$ & $\begin{array}{c}\text { No. of Patients } \\
\mathbf{N = 1 0 1}\end{array}$ & Percentage \\
\hline $\mathrm{T} 1$ & 5 & $4 \%$ \\
\hline $\mathrm{T} 2$ & 46 & $42 \%$ \\
\hline $\mathrm{T} 3$ & 48 & $44 \%$ \\
\hline $\mathrm{T} 4 \mathrm{a}$ & 11 & $10 \%$ \\
\hline $\mathrm{T} 4 \mathrm{~b}$ & 0 & 0 \\
\hline Table 4: Tumour Staging of Cancer Patients (n=110) \\
\hline
\end{tabular}




\begin{tabular}{|c|c|c|}
\hline Node Stage & No. of Patients & Percentage \\
\hline N0 & 64 & $58.18 \%$ \\
\hline N1 & 26 & $23.63 \%$ \\
\hline N2a & 12 & $10.90 \%$ \\
\hline N2b & 4 & $3.63 \%$ \\
\hline N2c & 2 & $1.81 \%$ \\
\hline N3 & 2 & $1.81 \%$ \\
\hline \multicolumn{2}{|c|}{ Table 5: Nodal Staging in Cancer Larynx Patients (n=110) } \\
\hline
\end{tabular}

Cervical lymphadenopathy was present in 56 (41.82\%) patients and level II cervical lymphadenopathy was the commonest in $42(63.63 \%)$ patients. In cancer larynx patients, most patients presented with T3 stage present in 48 (44\%) patients. N1 staging was present in $26(23.63 \%)$ patients; $1(0.90 \%)$ patient had lung metastasis and 1 $(0.90 \%)$ patient had skeletal metastasis. Most of the patients presented with stage III cancer in 43 (39.09\%) patients. (Table 4 and 5).

\begin{tabular}{|c|c|}
\hline Level of Differentiation & Cancer Larynx $(n=110)$ \\
\hline Well differentiated & $14(12.72 \%)$ \\
\hline Moderately differentiated & $62(56.36 \%)$ \\
\hline Poorly differentiated & $33(30.00 \%)$ \\
\hline Basaloid & $1(0.90 \%)$ \\
\hline \multicolumn{2}{|c|}{$\begin{array}{l}\text { Table 6: Level of Differentiation in } \\
\text { Squamous Cell Carcinoma Larynx }\end{array}$} \\
\hline
\end{tabular}

\begin{tabular}{|c|c|}
\hline Other Parameters & Cancer Larynx $(n=110)$ \\
\hline Necrosis & 80 \\
\hline Mitotic figures-Abundant & 36 \\
\hline Mitotic figures-Few & 69 \\
\hline Lymphocytic infiltration & 75 \\
\hline Keratinisation & 47 \\
\hline \multicolumn{2}{|c|}{$\begin{array}{c}\text { Table 7: Other Histopathological } \\
\text { Parameters in Cancer Larynx Patients }\end{array}$} \\
\hline
\end{tabular}

Squamous cell carcinoma was the histopathological variant seen in all patients in our study. Moderately differentiated squamous cell carcinoma was the most common squamous cell carcinoma variant seen present in 62 (56.36\%) patients, poorly differentiated in 33 (30.00\%) patients, well differentiated in $14(12.72 \%)$ patients and basaloid variant seen in $1(0.90 \%)$ patient. Necrosis was the most common histopathological parameter seen in 80 (72.72\%) patients. (Table 6 and 7).

\section{DISCUSSION}

The age distribution of patients ranged from 24 to 92 years of age with mean age of $51.92 \pm 13.06$ years. There were 110 patients with cancer larynx in our study, out of which 96 (87.27\%) patients were males and $14(12.72 \%)$ patients were females. It was observed in our study that cancer larynx was more common in males than females with male-tofemale ratio was 6.8:1.

Pain on swallowing was the commonest complaint present in 101 (91.81\%) patients followed by difficulty in swallowing complaint present in $93(86.91 \%)$ patients. It was found that most of the cancer larynx patients presented to hospital within 3 months of onset of symptoms. There were $68(61.81 \%)$ patients with pain on swallowing as commonest complaint presented within 3 months of onset of symptoms. Yerma A et al.[7] found hoarseness of voice $(73.92 \%)$ as commonest complaint followed by dysphagia (50.95\%) and pain in throat (25.59\%) in patients with cancer larynx.
It was observed that most patients presented to hospital within 3 months of onset of symptoms or at the most between 3 to 6 months' duration. It was because symptoms of cancer larynx are noticed early by the patients as these symptoms hinder in day-to-day activity of patients, which leads them for early consultation at the hospital.

Smoke tobacco consumption was present in 104 (94.54\%) patients, smokeless tobacco consumption was present in $12(10.90 \%)$ patients and alcohol consumption was present in $94(85.45 \%)$ patients with cancer larynx. Prevalence of smokeless tobacco in Middle East in relation to age reflects major changes over the decades in the use of smokeless tobacco. ${ }^{[8]}$ In 1970, 2.2\% of white male adults aged 18 to 24 years used chewing tobacco or snuff. The prevalence was higher at successively older ages, peaking at $11.8 \%$ among men 65 years or older. In 1991, the age trends were reversed with $10.4 \%$ of $18-24$ year olds using the products and fewer older persons using them: $7.9 \%$ of 25-34 year olds, $5.4 \%$ of $35-44$ year olds, $3.8 \%$ of $45-64$ year olds and $5.5 \%$ of individuals 65 years of age and older.[9] A study was conducted by Saedi B et al.[10] in which $88.5 \%$ patients were tobacco smokers with most of the patients (72.4\%) were in the 5th and 6th decades of their life.

In a study by Markou $\mathrm{K}$ et al[11] out of 1,088 patients with laryngeal cancer, $86.8 \%$ were smokers, $5.6 \%$ nonsmokers and $7.6 \%$ ex-smokers and $70 \%$ of patients were at the $6^{\text {th }}$ and $7^{\text {th }}$ decade of life. Tobacco is an agricultural product processed from the fresh leaves of plants in the genus Nicotiana. The smoke from tobacco elicits carcinogenic effects on the tissues of the body that are exposed to the smoke and consists of 43 carcinogens including polycyclic hydrocarbons and nitrosamines. In a study by Choi SY et al.[12] heavy drinkers (Males who consumed 90 grams daily of ethanol) had an approximately 11-fold risk of laryngeal cancer compared with non-drinkers.

There were $43(44.79 \%)$ male patients and 7 (50\%) female patients with less than 100 grams per day protein intake was the commonest, $41(42.70 \%)$ male patients and 9 (64.28\%) female patients with 41 to 50 grams per day fat intake was the commonest and $40(41.66 \%)$ male patients with 2001 to $3000 \mathrm{kcal} /$ day energy intake and 5 (35.71\%) female patients with less than $2000 \mathrm{kcal} /$ day energy intake was the commonest. In a study by Farhangfar A et al[13] loss of appetite, difficulty chewing, dry mouth, thick saliva and pain were individual symptoms that significantly associated with reduced dietary intake in a cohort of head and neck cancer patients.

The most common site involved was supraglottis in 70 (63.63\%) patients followed by glottis in 23 (20.90\%) patients than transglottis in $10(9.09 \%)$ patients and lastly subglottis in $7(6.36 \%)$ patients. Trigg et al[14] observed that the commonest subsite involved was supraglottis (53\%) followed by glottis (39\%), transglottis (7\%) and subglottis (1\%).

Ulceroproliferative growth pattern was seen in 97 (88.18\%) patients. Rousseau A et al[15] observed that cancer larynx usually presents as ulceroproliferative lesion. Ulceroproliferative pattern was seen commonly in cancer larynx, which could be due to friction of mucosal surfaces while eating and swallowing.

There was laryngeal widening present in 16 (14.54\%) patients, laryngeal tenderness present in $7(6.36 \%)$ patients and absent laryngeal crepitus in $2(1.81 \%)$ patients. 
In a study by Chen SA et al[16], 63 cases of laryngeal cancer with extralaryngeal spread were identified, out of which anterior spread by thyroid cartilage penetration occurred in $44 \%$ cases, followed by thyroid widening seen in $33 \%$ cases.

Cervical lymphadenopathy was present in 56 (41.82\%) patients and level II cervical lymphadenopathy was the commonest in $42(63.63 \%)$ patients. Dos Santos CR et al[17] found that lymph node metastasis was seen in 80 patients with advanced squamous cell carcinoma of larynx, out of which metastases were concentrated within level II in 59\% of cases, level III in $17 \%$ of cases, level IV in $11 \%$ of cases and level V in $6 \%$ of cases. Most patients presented with T3 stage present in 48 (43.63\%) patients. Markou K et al[11] observed T3 stage (32\%) as the most common presentation in cancer larynx patients. N1 staging was most common presentation in patients with cervical lymphadenopathy present in 26 (23.63\%) patients. In a study by Markou $\mathrm{K}$ et al[11] on laryngeal cancer, $\mathrm{N} 1$ stage was commonest presentation present in $26(23.63 \%)$ patients; $1(0.90 \%)$ patient had lung metastasis and $1(0.90 \%)$ patient had skeletal metastasis.

Papac RJ ${ }^{[18]}$ observed that $75 \%$ of patients with distant metastases had pulmonary deposits. Patients with distant metastasis usually present in late stage of disease as most of them belonged to rural area with poor medical facility, transportation and belief in religious ritual and traditional medicines. Most of the patients presented with stage III cancer in 43 (39.09\%) patients. Similar findings were seen in a study by Markou K et al.[11] It was observed in our study that patients usually presented with late stage disease which was because of self-neglect, failure to seek medical care early in the course of disease and few of them were taking different forms of Indian medicine for long duration. Squamous cell carcinoma was the histopathological variant seen in all patients in our study.

Moderately differentiated squamous cell carcinoma was the most common squamous cell carcinoma variant seen present in $62(56.36 \%)$ patients, poorly differentiated in 33 (30\%) patients, well differentiated in $14(12.72 \%)$ patients and basaloid variant seen in $1(0.90 \%)$ patient. In a study by Thakur $S$ et al[19], squamous cell carcinoma was the commonest histological type seen in $98.6 \%$ cases with laryngeal cancer. Busquets JM et al[20] conducted a study on head and neck squamous cell carcinoma and concluded that most of the patients (55.5\%) had moderately-differentiated squamous cell carcinoma. Necrosis was the most common histopathological parameter seen in $80(72.72 \%)$ patients. Necrosis in histopathological reporting is associated with high $\mathrm{T}$ classification and high $\mathrm{N}$ classification and thus poor prognosis of disease.[21]

\section{CONCLUSION}

- Majority of patients of carcinoma larynx had presenting symptom of pain on swallowing.

- Chronic tobacco and alcohol consumption was the most common aetiological factor in our study.

- Majority of patients had inadequate dietary intake as per recommended dietary allowance.

- Supraglottis was the most common subsite involved.

- The most common clinical presentation was ulceroproliferative growth pattern.
- More than half of the patients presented with cervical lymphadenopathy.

- Most of the patients were diagnosed at stage III of cancer.

- Squamous cell carcinoma was the most common histopathological type seen and moderately differentiated squamous cell carcinoma was the most common differentiation variant observed.

\section{REFERENCES}

1. Ridge JA, Glisson BS, Lango MN, et al. Head and neck tumours in Pazdur R, Wagman LD, Camphausen KA, Hoskins WJ, (Eds) cancer management: A Multidisciplinary approach 2008;11.

2. Maier $\mathrm{H}$, Weidauer $\mathrm{H}$. Alcohol drinking and tobacco smoking are the chief risk factors for ENT tumours. Fortschr Med 1995;113(11):157-60.

3. Schaal C, Chellappan PS. Nicotine mediated cell proliferation and tumour progression in smoking related cancers. Mol Cancer Res 2014;12(1):14-23.

4. Smeul W, Beaken, MD. Laryngeal cancer (cancer of larynx). Armenian Health Network, Health am Retrieved 2007;03-22.

5. Kapil U, Singh P, Bahadur S, et al. Assessment of risk factors in laryngeal cancer in India: a case control study. Asian pacific J Prev 2005;6(2):202-7.

6. Zia MR, Murtaza G, Nadeem Raza, et al. Overview of clinical presentation of laryngeal malignancy. Biomedica 2005;21(19):2-4.

7. Yerma A, Mehta S, Panda NK, et al. Presentation of carcinoma larynx and laryngopharynx: an analysis of 840 cases. Indian Journal of Otolaryngology 1990;42(2):50-3.

8. Phukan RK, Ali MS, Chetia CK, et al. Betel nut and tobacco chewing; potential risk factors of cancer of oesophagus in Assam, India. Br J Cancer 2001;85(5):661-7.

9. Redmond DE. Tobacco and cancer: the first clinical report, 1761. N Engl J Med 1970;282(1):18-23.

10. Saedi B, Razmpa E, Sadeghi M, et al. The epidemiology of laryngeal cancer in a country on esophageal cancer belt. Indian J Otolaryngol Head Neck Surg 2009;61(3):213-7.

11. Markou K, Christoforidou A, Karasmanis I, et al. Laryngeal cancer: epidemiological data from Northern Greece and review of the literature. Hippokratia 2013;17(4):313-8.

12. Choi SY, Kahyo H. Effect of cigarette smoking and alcohol consumption in the aetiology of cancer of the oral cavity, pharynx and larynx. Int J Epidemiol 1991;20(4):878-85.

13. Farhangfar A, Makarewicz M, Ghosh S, et al. Nutrition impact symptoms in a population cohort of head and neck cancer patients: multivariate regression analysis of symptoms on oral intake, weight loss and survival. Oral oncol 2014;50(9):877-83.

14. Trigg DJ, Lait $\mathrm{M}$, Wenig BL. Influence of tobacco and alcohol on the stage of laryngeal cancer at diagnosis. Laryngoscope 2000;110(3 Pt 1):408-11.

15. Rousseau A, Badoual C. Head and neck: squamous cell carcinoma: an overview. Atlas Genet Cytogenet Oncol Haematol 2012;145-55.

16. Chen SA, Muller S, Chen AY, et al. Patterns of extralaryngeal spread of laryngeal cancer: thyroid cartilage penetration occurs in a minority of patients with extralaryngeal spread of laryngeal squamous cell cancers. Cancer 2011;117(22):5047-51. 
17. Dos Santos CR, Goncalves Filho J, Margrin J, et al. Involvement of level I neck lymph nodes in advanced squamous carcinoma of the larynx. Ann Otol Rhinol Laryngol 2001;110(10):982-4.

18. Papac RJ. Distant metastases from head and neck cancer. Cancer 1984;53(2):342-5.

19. Thakur S, Chaturvedi VN, Sibgh AK, et al. Pattern of ear, nose, pharynx, larynx and oesophagus cancers in a rural based hospital. Ind J Otolaryngol Head Neck Surg 2001;53(2):93-9.
20. Busquets JM, García HA, Trinidad Pinedo J, et al. Clinicopathological characteristics of head and neck squamous cell carcinoma in peurto ricans. P R Health Sci J 2003;22(3):259-64.

21. Manjari M, Popli R, Paul S, et al. Prevalence of oral cavity, pharynx, larynx and nasal cavity malignancies in Amritsar, Punjab. Indian Journal of Otolaryngology and Head and Neck Surgery 1996;48(3):191-5. 